\title{
Evaluation of the comparison of anti-depressant effects of oral fluoxetine and riluzole in albino rats by using the forced swimming test model
}

\author{
Hansraj Kumar ${ }^{1}$, Akash Chandra ${ }^{1 *}$, Uma Shankar Prasad Kesari ${ }^{2}$, Rajiv Kumar ${ }^{2}$
}

\author{
${ }^{1}$ Department of Pharmacology, Shaheed Nirmal Mahto Medical College and Hospital, Dhanbad, Jharkhand, India \\ ${ }^{2}$ Department of Pharmacology, RIMS, Ranchi, Jharkhand, India
}

Received: 31 January 2021

Accepted: 03 March 2021

\author{
*Correspondence: \\ Dr. Akash Chandra, \\ Email: drakash1984@gmail.com
}

Copyright: (C) the author(s), publisher and licensee Medip Academy. This is an open-access article distributed under the terms of the Creative Commons Attribution Non-Commercial License, which permits unrestricted non-commercial use, distribution, and reproduction in any medium, provided the original work is properly cited.

\begin{abstract}
Background: Depression is a group of disorders results from a combination of multiple etiologic factors- genetic, biochemical, psychodynamic and socio-environmental. A depression consists of following clinical features as sadness, apathy, changes in sleep pattern, impaired concentration, feeling of shame or guilt and thoughts of dying or death. Fluoxetine and riluzole both are used for the treatment of depression in human being. Fluoxetine is SSRI (selective serotonin reuptake inhibitors) and riluzole is anxiolytic and mood stabilizer.

Methods: Healthy male albino rats weighing between 150-200 grams were taken for the present study. Study animals were divided into three groups randomly with each group consisting of ten animals. Drugs were powdered with help of mortar and pestle and mixed in gum acacia solution. Appropriate volume of the freshly prepared solution was administered orally daily between 9 am to 10 am to all animal as per their individual body weight. Group A administered $1 \mathrm{ml}$ of $0.9 \%$ normal saline orally and serves as control group. Group B administered $0.4 \mathrm{mg}$ of fluoxetine orally. Group $\mathrm{C}$ administered $2 \mathrm{mg}$ of riluzole orally. Animals were evaluated for antidepressant activity using model- forced swimming test.

Results: The results in the forced swimming test were assessed by duration of immobility in last 4 minutes of total 6 minute test duration. Antidepressant activity is indicated by the reduction in the duration of immobility i.e. lesser the duration more the efficacy. The results have been expressed as mean \pm standard deviation of duration of immobility in seconds during 6 minute period.

Conclusions: There was significant difference in antidepressant activity of fluoxetine with antidepressant activity of riluzole. Riluzole showed antidepressant activity after two weeks of starting the drugs.
\end{abstract}

Keywords: Anxiolytic, Forced swimming test, Psychodynamic, SSRI

\section{INTRODUCTION}

Depression is a major affective disorder. It belongs to the heterogeneous group of mood disorders characterized by extreme exaggerations and disturbances of mood, which adversely affect cognition and psychomotor functions. ${ }^{1}$ Depression is diagnosed when depressed mood on a daily basis persist for a minimum duration of 2 weeks. A depressive episode may be characterized by sadness, apathy, changes in sleep pattern, impaired concentration, feeling of shame or guilt and thoughts of dying or death. ${ }^{2}$ Depression must be distinguished from normal grief, sadness, disappointment and the dysphoria or demoralization associated with medical illness and from bipolar disorder in which depression alters with hypomania or mania. The condition is often under diagnosed and frequently undertreated. ${ }^{3}$ Major depressive disorder is a mental disorder common in psychiatric practice wherein a patient presents with at least one of the two major symptoms, constant sadness or anhedonia, accompanied by at least five of these nine secondary symptoms for at least two weeks. ${ }^{4}$ Although depression can occur at any age, adults 18 to 29 years of age experience the highest rates of major depression during any given year. ${ }^{5}$ Women are at increased risk of depression from early adolescence until their mid-50s, with a lifetime 
rate that is 1.5 to 3 times greater than for men..$^{5}$ The estimated lifetime prevalence of major depression in individuals aged 65 to 80 years recently was reported to be $20.4 \%$ in women and $9.6 \%$ in men. ${ }^{6}$ Depressive disorders are common during adolescence, with co-morbid substance abuse, suicide attempts and deaths occurring frequently in these patients. ${ }^{7}$ In the global burden of disease (GBD) study conducted by the World Health Organization, unipolar major depression ranked second among all diseases in terms of disability-adjusted lifeyears. ${ }^{8}$ At its worst, it can lead to suicide, a tragic fatality associated with the loss of about 850,000 lives every year globally. ${ }^{9}$ A recent meta-analysis found that the heritability of liability for major depression was $37 \%$, whereas the remaining $63 \%$ of the variance in liability was caused by individual specific environment. ${ }^{10}$ Monozygotic twins have a higher concordance rate $(46 \%)$ than dizygotic siblings $(20 \%) .{ }^{11}$ Biochemical factors include decrease in level of neurotransmitters like nor-epinephrine and serotonin in the brain. ${ }^{12}$ Crucial life events, particularly the death or loss of a loved one or an emotional trauma can precede the onset of depression. ${ }^{13}$

\section{METHODS}

\section{Place of study}

The entire experiment was carried out in post graduate laboratory Department of Pharmacology and therapeutics, Rajendra Institute of Medical Sciences, Ranchi.

\section{Study design}

It was a randomized, open label, interventional, comparative, depressive model animal study.

\section{Study duration}

After 14 days period of acclimatization to the laboratory condition, the study was done for 42 days. The immobility time (in seconds) were recorded on $0,7^{\text {th }}, 14^{\text {th }}, 21^{\text {st }}, 28^{\text {th }}$, $35^{\text {th }}$ and $42^{\text {nd }}$ day of treatment by forced swimming test (FST) models.

\section{Animal}

Healthy male wistar albino rats weighing between 150-200 grams were taken for the present study. The animals were kept in clean and dry standard size cages (10 rats per cage).

\section{Inclusion criteria}

Healthy and active male wistar albino rats. Weight of the animal used was 150-200 grams.

\section{Exclusion criteria}

Diseased and inactive rats were excluded from study. Female rats were excluded. Rats with weight less than 150 grams and above 200 grams were excluded.
Tabble 1: Grouping of animals.

\begin{tabular}{|lll|}
\hline Group & No. of rats & Drug \\
\hline A (Control) & 10 & $0.9 \%$ normal saline only \\
\hline B (Fluoxetine) & 10 & Fluoxetine \\
\hline C (Riluzole) & 10 & Riluzole \\
\hline
\end{tabular}

\section{Equipment's}

Cylindrical tanks $(30 \mathrm{~cm}$ height $\times 30 \mathrm{~cm}$ diameters $)$, adhesive tape, syringes, $60 \mathrm{w}$ bulb, towel, tissue paper, animal feeding tube (gavage tube), sterilized cotton, $1 \%$ gum acacia suspension and stopwatch.

\section{Administration of drugs with doses}

Study animals were divided into three groups randomly with each group consisting of ten animals. Drugs were powdered with help of mortar and pestle and mixed in gum acacia solution. Appropriate volume of the freshly prepared solution was administered orally daily between 9 am to 10 am to all animal as per their individual body weight. Group A administered $1 \mathrm{ml}$ of $0.9 \%$ normal saline orally and serves as control group. Group B administered $0.4 \mathrm{mg}$ of fluoxetine orally. Group $\mathrm{C}$ administered $2 \mathrm{mg}$ of riluzole orally.

\section{Testing procedure}

Animals were evaluated for antidepressant activity using model- forced swimming test.

\section{Forced swimming test ${ }^{14}$}

The forced swimming model used in the present study was similar to the original method described by Porsolt et al during 1977-78 for testing antidepressant activity of new compound. The animals were forced to swim in a plastic cylinder measuring $30 \times 30 \mathrm{~cm}$ containing water up to a depth of $20 \mathrm{~cm}$ at room temperature. After an initial 2 minute period of vigorous activity, each animal assumed a typical immobile posture. The rat was considered immobile when it remained floating in the water without struggling, making only minimum movements of its limbs necessary to keep its head above water. The rats were subjected to a 15-minute training session under similar conditions, 24 hour before the test. The total duration of immobility was recorded for next 4 minutes of total 6 minute duration of test. The changes in immobility duration were studied after administering drugs in separate group of animals. Following swimming sessions, the rats were dried with towel and placed in a cylinder heated under $60 \mathrm{w}$ bulb. The animals were allowed to dry for 15 minutes before returning them to their respective cages.

\section{Statistical analysis}

All the results of testing on different days were carefully recorded in Microsoft excel 2010 software and then 
statistical analysis of data was carried out using IBM SPSS software version 23. One way ANOVA test was used to compare the effect of drugs on different groups. Tukey's HSD test was employed for post-hoc analysis of significant overall difference between the groups

\section{RESULTS}

\section{Forced swimming test (FST)}

The results in the forced swimming test were assessed by duration of immobility in last 4 minutes of total 6 minute test duration. Antidepressant activity is indicated by the reduction in the duration of immobility i.e. lesser the duration more the efficacy. The results have been expressed as mean \pm standard deviation of duration of immobility in seconds during 6 minute period.

Table 1: Sequential changes in immobility time (in seconds) by FST in all groups on $0,7^{\text {th }}, 14^{\text {th }}, 21^{\text {st }}, 28^{\text {th }}$, $35^{\text {th }}$ and $42^{\text {nd }}$ day.

\begin{tabular}{|llll|}
\hline Day & Gr A & Gr B & Gr C \\
\hline $\mathbf{0}$ & $48.0 \pm 3.97$ & $48.3 \pm 2.66$ & $48.4 \pm 1.64$ \\
\hline $\mathbf{7}$ & $48.1 \pm 2.02$ & $46.3 \pm 2.40$ & $46.6 \pm 1.95$ \\
\hline $\mathbf{1 4}$ & $47.8 \pm 2.97$ & $43.4 \pm 2.67$ & $44.7 \pm 2.05$ \\
\hline $\mathbf{2 1}$ & $47.7 \pm 4.85$ & $40.3 \pm 2.31$ & $42.9 \pm 2.33$ \\
\hline $\mathbf{2 8}$ & $47.8 \pm 3.93$ & $36.7 \pm 3.09$ & $40.1 \pm 2.13$ \\
\hline $\mathbf{3 5}$ & $46.9 \pm 3.07$ & $33.1 \pm 2.76$ & $39.8 \pm 1.93$ \\
\hline $\mathbf{4 2}$ & $47.3 \pm 3.09$ & $32.1 \pm 2.64$ & $37.4 \pm 1.77$ \\
\hline
\end{tabular}

All the values are expressed in mean \pm standard deviation.

Table 2: Comparison between group $\mathbf{A}$ and group $\mathbf{B}$.

\begin{tabular}{|llllllll|}
\hline & Day 0 & Day 7 & Day 14 & Day 21 & Day 28 & Day 35 & Day 42 \\
\hline Gr. A & $48.0 \pm 3.97$ & $48.1 \pm 2.02$ & $47.8 \pm 2.97$ & $47.7 \pm 4.85$ & $47.8 \pm 3.93$ & $46.9 \pm 3.07$ & $47.3 \pm 3.09$ \\
\hline Gr. B & $48.3 \pm 2.66$ & $46.3 \pm 2.40$ & $43.4 \pm 2.67$ & $40.3 \pm 2.31$ & $36.7 \pm 3.09$ & $33.1 \pm 2.76$ & $32.1 \pm 2.64$ \\
\hline Mean difference & 0.3000 & 5.6000 & 7.7000 & 9.6000 & 12.9000 & 14.2000 & 16.1000 \\
\hline P value & 0.995 & 0.0000 & 0.0000 & 0.0000 & 0.0000 & 0.0000 & 0.0000 \\
\hline
\end{tabular}

Table 3: Comparison between group A and group $\mathrm{C}$.

\begin{tabular}{|llllllll|}
\hline & Day 0 & Day 7 & Day 14 & Day 21 & Day 28 & Day 35 & Day 42 \\
\hline Gr. A & $48.0 \pm 3.97$ & $48.1 \pm 2.02$ & $47.8 \pm 2.97$ & $47.7 \pm 4.85$ & $47.8 \pm 3.93$ & $46.9 \pm 3.07$ & $47.3 \pm 3.09$ \\
\hline Gr. C & $48.4 \pm 1.64$ & $46.6 \pm 1.95$ & $44.7 \pm 2.05$ & $42.9 \pm 2.33$ & $40.1 \pm 2.13$ & $39.8 \pm 1.93$ & $37.4 \pm 1.77$ \\
\hline Mean difference & 0.4000 & 1.5000 & 4.0000 & 4.8000 & 7.0000 & 7.4000 & 9.9000 \\
\hline P value & 0.987 & 0.267 & 0.001 & 0.004 & 0.0000 & 0.0000 & 0.0000 \\
\hline
\end{tabular}

Table 4: Comparison between group $B$ and group $C$.

\begin{tabular}{|llllllll|}
\hline & Day 0 & Day 7 & Day 14 & Day 21 & Day 28 & Day 35 & Day 42 \\
\hline Gr. B & $48.3 \pm 2.66$ & $46.3 \pm 2.40$ & $43.4 \pm 2.67$ & $40.3 \pm 2.31$ & $36.7 \pm 3.09$ & $33.1 \pm 2.76$ & $32.1 \pm 2.64$ \\
\hline Gr. C & $48.4 \pm 1.64$ & $46.6 \pm 1.95$ & $44.7 \pm 2.05$ & $42.9 \pm 2.33$ & $40.1 \pm 2.13$ & $39.8 \pm 1.93$ & $37.4 \pm 1.77$ \\
\hline Mean difference & 0.1000 & 4.1000 & 3.7000 & 4.8000 & 5.9000 & 6.8000 & 6.2000 \\
\hline P value & 1.0000 & 0.0000 & 0.002 & 0.004 & 0.0000 & 0.000 & 0.0000 \\
\hline
\end{tabular}

\section{DISCUSSION}

The present study evaluated the possible antidepressant activity of the drugs fluoxetine and riluzole, by using the conventional experimental animal model of antidepressant activity: forced swimming test.

The results following these tests have been compared with that of standard antidepressant drug fluoxetine, and with $0.9 \%$ normal saline taken as control. The fore mentioned experimental model is widely used to screen newer and potential antidepressant drugs. There is a significant correlation between the efficacy of antidepressants in forced swimming and clinical effectiveness of the drugs. ${ }^{15}$
This test is quite sensitive and relatively specific to all major classes of antidepressants like tricyclics, selective serotonin reuptake inhibitors, monoamine oxidase inhibitors and atypical antidepressants. ${ }^{16}$ From Table 2 and 4 it's evident that fluoxetine showed significant antidepressant activity in comparison to normal saline from $7^{\text {th }}$ day with $p$ value of 0.000 for FST. In current study riluzole also showed significant antidepressant activity in comparison to normal saline, by means of reduced immobility time (Tables 3 and 4). Onset of antidepressant activity of riluzole was from day $14^{\text {th }}$. P value for FST was 0.001 at day $14^{\text {th }}$. Riluzole is a glutamatergic modulator with neuroprotective and plasticity-enhancing properties. 
Antidepressant activity of riluzole has the following basis: 1) Evidence supporting the favourable CNS therapeutic profile of riluzole includes a growing body of work showing that this agent has neuroprotective properties in animal models of brain ischemia, spinal cord injury, traumatic brain injury, Parkinson's disease, post-traumatic peripheral neuropathy and acute noise-induced hearing loss. ${ }^{17-20} 2$ ) It has been suggested that inhibition of tyrosine phosphorylation (which is observed in response to brain ischemia) may contribute to riluzole's neuroprotective properties against excitotoxic injury. ${ }^{21} 3$ ) In addition, riluzole was found to be neuroprotective in glutamateinduced toxicity in primary glial cell culture, as evidenced by decreases in lactate dehydrogenase activity and nitrite levels. $^{22}$

Riluzole, a neuroprotective agent with anticonvulsant properties, appears to be a promising candidate drug for the treatment of neuropsychiatric disorders. It is a glutamatergic modulator with diverse effects within the glutamatergic brain system, a system that is being increasingly linked with the pathophysiology of mood disorders.

\section{CONCLUSION}

From result of our study it can be concluded that riluzole showed significant antidepressant activity by forced swimming test in Wistar albino rat models. Riluzole showed antidepressant activity after two weeks of starting the drugs. There is significant difference in antidepressant activity of fluoxetine with antidepressant activity of riluzole. Riluzole have different but favourable pharmacological profile to be useful in treatment of major depressive disorder. Riluzole is the only drug approved by US FDA improves the survival in amyotrophic lateral sclerosis and can provide therapeutic benefits in the patients.

Funding: No funding sources

Conflict of interest: None declared

Ethical approval: The study was approved by the Institutional Ethics Committee

\section{REFERENCES}

1. Gupta SK. Drug Screening Methods. 3rd edn. Jaypee Brothers Medical Publishers; 2016:404.

2. Fauci AS, Braunwald E, Kasper DL, Hauser SL, Longo DL, Jameson JL, et al, eds. Harrison's principals of internal medicine. Vol 2. 19th edn. New York: McGraw Hill; 2015:2714-2717.

3. Suominen KH, Isometsa ET, Henriksson MM, Ostamo AI, Lonnqvist JK. Inadequate treatment for major depression both before and after attempted suicide. Am J Psychiatr. 1998;155(12):1778-80.

4. American Psychiatric Association. Diagnostic and statistical manual of mental disorders: DSM-IV. 4th edn. Washington (DC): American Psychiatric Association; 1994.
5. Teter CJ, Kando JC, Wells BG. Major depressive disorder. Basicmedical Key; 2016.

6. Steffens DC, Skoog I, Norton MC, Hart AD, Tschanz JT, Plassman BL, Wyse BW, Welsh-Bohmer KA, Breitner JC. Prevalence of depression and its treatment in an elderly population: the Cache County study. Archives of General Psychiatry. 2000;57(6):601-7.

7. Pompili M, Serafini G, Innamorati M, Dominici G, Ferracuti S, Kotzalidis GD, Serra G, Girardi P, Janiri L, Tatarelli R, Sher L. Suicidal behavior and alcohol abuse. Int $\mathbf{J}$ Environ Res Public Health. 2010;7(4):1392-431.

8. Ferrari AJ, Charlson FJ, Norman RE, Patten SB, Freedman G, Murray CJ, et al. Burden of depressive disorders by country, sex, age, and year: findings from the global burden of disease study 2010. PLoS Med. 2013;10(11):e1001547.

9. Jameson JL, Fauci AS, Kasper DL, Hauser SL, Longo DL, Loscalzo J, eds. Harrison's Principles of Internal Medicine. 19th edn. McGraw-Hill Professional; 2017.

10. Rogers SJ, Cavazos JE. Epilepsy. In: Dipiro JT, Talbert RL, Yee GC, Matzke GR, Wells BG, Posey LM, eds. Pharmacotherapy A pathophysiologic approach. 7 edn, McGraw Hill: New York; 2008:927.

11. Sullivan PF, Neale MC, Kendler KS. Genetic epidemiology of major depression: review and metaanalysis. Am J Psychiatr. 2000;157(10):1552-62.

12. Brigitta B. Pathophysiology of depression and mechanisms of treatment. Dialogue Clin Neurosci. 2002;4(1):7-20.

13. Trauma emotional and psychological trauma. Available at: http://www.helpguide.org/articles/ptsdtrauma/emotional-and-psychological-trauma.html. Accessed on $20^{\text {th }}$ January 2021.

14. Porsolt RD, Bertin A, Jalfre M. Behavioural despair in mice: a primary screening test for antidepressants. Arch Int Pharmacodyn Ther. 1977;229(2):327-36.

15. Turner EH, Matthews AM, Linardatos E, Tell RA, Rosenthal R. Selective publication of antidepressant trials and its influence on apparent efficacy. N Engl J Med. 2008;358(3):252-60.

16. Steru L, Chermat R, Thierry B, Simon P. The tail suspension test: a new method for screening antidepressants in mice. Psychopharmacology. 1985;85(3):367-70.

17. Ates O, Cayli SR, Gurses I, Turkoz Y, Tarim O, Cakir $\mathrm{CO}$, et al. Comparative neuroprotective effect of sodium channel blockers after experimental spinal cord injury. J Clin Neurosci. 2007;14(7):658-65.

18. Schwartz G, Fehlings MG. Evaluation of the neuroprotective effects of sodium channel blockers after spinal cord injury: improved behavioral and neuroanatomical recovery with riluzole. J Neurosurg. 2001;94(2 Suppl):245-56.

19. Benazzouz A, Boraud T, Dubédat P, Boireau A, Stutzmann JM, Gross C. Riluzole prevents MPTPinduced parkinsonism in the rhesus monkey: a pilot study. Eur J Pharmacol. 1995;284(3):299-307. 
20. Wang J, Hameg A, Dib M, Puel JL. Neuroprotective effect of riluzole in acute noise-induced hearing loss. Neuroreport. 2005;16(10):1087-90.

21. Peyclit A, Keita H, Juvin P, Derkinderen P, Jardinaud F, Rouellé D, et al. Effects of riluzole on N-methyl-Daspartate-induced tyrosine phosphorylation in the rat hippocampus. Brain Res. 2001;903(1-2):222-5.
22. Dagci T, Yilmaz O, Taskiran D, Peker G. Neuroprotective agents: is effective on toxicity in glial cells? Cell Mol Neurobiol. 2007;27(2):171-7.

Cite this article as: Kumar $\mathrm{H}$, Chandra A, Kesari USP, Kumar R. Evaluation of the comparison of anti-depressant effects of oral fluoxetine and riluzole in albino rats by using the forced swimming test model. Int J Basic Clin Pharmacol 2021;10:391-5. 